\title{
Ethiopia: \\ Indigenous Conflict Resolution Mechanism of Shekacho People and Its Role in Promoting Peace and Good Governance
}

\author{
Wasihun Bezabih BEKELE \\ Admasu Adraro AKAKO
}

\begin{abstract}
This research sought to explore the Indigenous Conflict Resolution Mechanism (ICRM) of Shekacho people in Sheka Zone, South West Ethiopia. The ICRM of Shekacho has organized procedure, structure, and actors who actively participate in the system. The procedures in ICRM of Shekacho people pass through two sequential phases of conflict resolution-intervention and resolution. However, despite this reality, it has no strong or formal relationship with the modern conflict adjudication system. Thus, this research ague for the provision of support from the government and establishing an enabling system for building a working relationship between the indigenous system and the modern adjudication system. Furthermore, higher academic institutions need to play their role by giving awareness-raising training for concerned stakeholders

Wasihun Bezabih BEKELE Departemnt of Governance regarding the role of indigenous knowledge in modern governance.
\end{abstract} and Development Studies Mizan-Tepi University

Email: wasihunb@mtu.edu.et

Admasu Adraro AKAKO

Departemnt of Governance and Development Studies Mizan-Tepi University

Conflict Studies Quarterly

Issue 38, January 2022, pp. 3-22

DOI: $10.24193 / \mathrm{csq} .38 .1$

Published First Online: 05 January / 2022
Keywords: conflict, indigenous conflict resolution, clan leaders, elders, mikirecho.

\section{Introduction}

Peace is essential not only for the very survival of humans at individual and collective levels but also for achieving human development at large. Therefore, personal and societal wellbeing, and economic development and prosperity are possible only in the 
presence of peace (McCandless \& Bangura, 2007). However, though peace is critically required, there are different factors that cause conflict in human life. According to Fisher (1990), Bukari (2013, cited in Masenya, 2021), and Nicholson (1992), conflict is a disagreement between two or more than two parties in their relationship due to their held inconsistent goals or values. Based on the scholars' definition it can be concluded that conflict is a situation that necessarily involves at least two parties running interdependently holding different goals and values.

Therefore, since conflict is natural, what matters is not how to duck conflict but how to resolve it. Here, the concept of conflict resolution comes to the front. In this study, when we say conflict resolution, we are referring to the indigenous one. Thus, in this context, conflict resolution is the mechanism through which conflict is resolved by using widely shared and deeply-rooted social values and norms. To Osei-Hwedie (2012), indigenous conflict resolution is a community process involving the identification of the root cause of the problem and bringing all parties involved to address the underlying issue. Therefore, the process of indigenous conflict resolution ends with the guilty admiting wrongdoing, leading to reconciliation which consequently involve compensation or just forgiveness (Sandu, 2018, Chereji \& Sandu, 2018).

Ethiopia is a multicultural state where different ethnic groups had developed their unique ICRM. According to Enyew (2014), Ethiopia is known with having different ethnic groups; as a result, each ethnic group has different conflict resolution mechanisms. Among many, the Oromo (Gada), the Amhara (Yeager-Shimagle), the Gurage (Yejewoka Shengo), and the Wolayata (Deira Cimma) are ICRMs playing significant role not only in reconciliation but also constructing social welfare (Zewude, 2002, cited in Mengesha, Yesuf, \& Gebre, 2015). The Shekacho community is not exceptional. ICRMs are parts of a social system that play an important role in maintaining peace and order by conciliating, maintaining, and improving social relationships (Osei-Hwedie \& Rankopo, 2008, cited in Endalcachew, Gashaw, \& Zelalem, 2015). ICRMs use local actors (elders, chiefs, religious leaders,and clan leaders) and community-based judicial decision-making mechanisms to resolve conflict.

Gebre-Egziabher (2014) pointed that indigenous conflict resolution mechanisms help control and resolve conflicts in Africa, in general, and in Ethiopia, in particular. Southern Ethiopia is known for its ethnic diversity and it is believed to be the home of many multilingual and multicultural societies. Shekacho is one among the many ethnic communities living in southwest Ethiopia. The Shekacho community has developed an age-old system of conflict resolution. This system comprises the structure, mechanisms, processes, and institutions through which the people manage their differences and maintain social solidarity. Though such indigenous mechanisms of resolving the conflict have tremendous advantages, practically, Ethiopia, like most countries, has failed to recognize it. In agreement with this idea, Mussa et al. (2017) argued that, in Ethiopia, the roles of 
elders and clan leaders in conflict resolution have been overlooked by government and non-government organizations. ICRMs are considered as an alternative when mediation by the formal legal systems fails to fit into the practical local situations (Mohammed \& Beyene, 2016, cited in Mussa et al., 2017).

\section{Statement of the Problem}

Ethiopia is a country in which various ethnic groups live together. Each ethnic group has its way of resolving conflicts. Different communities have distinct traditional settings and relationships, where a traditional mechanism could play a significant role in resolving and preventing violent conflicts. Concerning this idea, Bahru Zewude (2002, cited in Mengesha et al., 2015) stated that throughout Ethiopia, among the Oromo (Gada), the Amhara (Yeager-Shimagle), the Gurage (Yejewoka Shengo), the Wolayata (Deira Cimma), and other linguistic or ethnic groups play a significant role not only in reconciliation but also constructing social welfare.

Unlike the modern conflict resolving system, the indigenous institutions are working to resolve conflict and thereby restore the broken social relationships. Researches have been done by different authors in this regard. The studies explored diverse causes of conflict and mechanisms of conflict resolutions based on the socio-economic and environmental settings of their study societies. For example, the cause of conflict in most of Oromia is a scarce resource (Muchie \& Baye, 2015). Different from this, Melese (2008, cited in Awash, 2015) stated that administrative restructuring, abuse of power, and differences in social status are the major sources of conflict among the Wolayita of Southern Ethiopia. ICRMs have an irreplaceable role in resolving conflict. With this, Olsen (2010), strongly argue that conserving traditional practices and values is as important as conserving the natural environment. However, this can only be realized when the cultural and traditional aspects of human society are systematically and scientifically studied and documented.

Shekaco people, like many others, have faced multifaceted conflicts and have simultaneously developed their mechanism of conflict resolution. The ICRM of Shekacho people plays a paramount role in upholding sustainable social welfare. However, as long as researchers' knowledge is concerned, there has been no observable empirical effort to study this cultural endowment of Shekacho people. This has affected not only the development and enrichment of the traditional aspect of Shekacho people but also fails to reveal the history and the attributes of ICRM to other societies. This inspired the researchers to undertake the study on this indigenous cultural practice of the Shekacho people on the following research questions:

1. What are the sources and types of conflict mostly arising in the community of Shekacho people?

2. What are the procedures used and actors involved in ICRM of Shekacho people? 
3. What is the nexus between ICRM of Shekacho people and the formal court system?

4. What is the communities trust, and preference to ICRM of Shekacho?

5. What are the challenges that the ICRM of Shekacho People currently facing?

6. What will be the possible role/share of all stakeholders in the preservation of this institution of Shekacho people?

\section{Research Design}

As the study aimed at exploring ICRM of Shekacho people of South-West of Ethiopia, the study followed a qualitative descriptive approach. In this regard, the study dominantly employed a qualitative research approach.

\section{Sampling}

Purposive sampling was used to select research participants and districts. Three districts, such as Masha, Andracha, and Yeki, were purposely selected. This is because the Shekacho people predominantly live in the Masha and Andracha districts of Sheka Zone, the people also live in some kebeles of Yeki district, namely Kubito and Ermichi. As a result, the researchers strongly believe that these areas are more relevant to the topic that was studied and have abundant information regarding the ICRM of the Shekacho people.

For the selection of research participants, from the three districts, the none-probability sampling technique was preferred to select elders of both sexes who have better knowledge and understanding of the culture and tradition of the people. From the non-probability sampling techniques, a snowballing sampling technique was typically employed. Snowball sampling is often used to find and recruit "hidden populations" that is, groups not easily accessible to researchers through other sampling strategies (Mack, 2005).

Accordingly, 21 elders and clan leaders were selected. Moreover, using the judgmental sampling technique 7 experts and officials from the office of culture and tourism, and justice administration were selected and interviewed. Regarding FGD, three FGD sessions were conducted addressing 10 discussants in each FGD.

\section{Data collection}

Data were collected through semi-structured interviews and focus group discussion (FGD). An interview was held with elders and clan leaders, who commonly participate in the conflict resolution process and have experience in the ICRM. In addition, selected formal court judges, police officers, and experts in the culture, tourism, and sport department of the study area were interviewed. About FGD, it was held with elders and clan leaders who were selected based on their lived experience in ICRM and their recognition in the community. Issues regarding sources of conflict in the community, 
types of conflict, and structure, actors, and procedures of ICRM were discussed. Issues related with the communities views and knolegde of ICRM of Shekacho people and their preference to be governed by it, were addressed both in semi-structured interviews and FGD themes.

\section{Analysis and Interpretation Technique}

Qualitative research encompasses different data collection and analytical approaches to providea cultural and contextual description and interpretation of social phenomenon (Vaismoradi \& Snelgrove, 2019). Though there exist various techniques of analysis, it is not helpful to be overwhelmed with the variety because there is no concrete prescribed way to address the analysis process (Kawulich, 2004). However, as noted by Creswell (2007), data analysis in qualitative research consists of preparing and organizing the data for analysis (transcribing), reducing the data into themes through a process of coding and condensing the codes. This is the general process that researchers use, across many books, in qualitative research.

Therefore, in this study, the researchers employed a thematic analysis technique. In agreement with recommendations given by Braun \& Clarke (2006) and Vaismoradi \& Snelgrove (2019), the researchers followed this steps in thematically analyzing the data. First, getting familiar with the data, which involved reading the transcribed data and getting thoughtful about it. Secondly, generating initial codes, which involved highlighting the item of data that was considered to be potentially interesting across the entire data set. Thirdly, searching for themes, which meant going through initial codes and combined the ones that are similar to form a central them and sub-theme. At this stage, codes were collected under themes and subthemes based on their relationship. Fourthly, reviewing the themes, which meant that the generated themes were compared and checked against the coded extracts. Fifth, defining, refining, and naming themes; in thic case, the researchers defined and named each theme. An in-depth analysis for each theme was given to ensure that the themes are in accord with the overall concept of the data, and more importantly, they are about the research questions. Lastly, producing a final report; an analysis was given for each theme, and a report was written. The report consists of the interpretation of the analysis and discussion part.

\section{Result and Discussion}

\section{Types and sources of conflict in the community of the Shekacho people}

As researchers learned from literature, conflict may arise within family, between communities, and nations (Gowok, 2008). Thus, there may be a different reason for conflicts arising at all levels. Conflict in Shekacho community also occurs due to different reasons and such conflicts also can be labeled as boundary conflict, conflict in marriage, and interpersonal conflict. 
Boundary conflict is the most occurring and common type of conflict among the Shekacho community. Boundary conflict in Shekacho community falls under two categories, clan boundary conflict and interpersonal boundary conflict. Clan boundary conflict is violent if not managed in time, and it is the biggest type of boundary conflict as it involves many families and members of each clan. Clan boundary conflict occurs if a boundary set between two clans is violated. Most of the time, the boundary is said to be violated if members of a particular clan pass a demarcated boundary and use the land for farming crops and planting coffee. Another form of boundary conflict is interpersonal boundary conflict which would occur if one of the neighbors passes the boundary and clear the land for agricultural use, and if a person enter into and uses the forest called Kobo which is held by a particular family for honey farming.

Kobo is part of forest land which is held by a person or a particular family. This land, according to the cultural practice of the community, will be gained by inheritance from the parent or relatives. Primarily, the Kobo serves for traditional honey farming and it is believed to be one of the great cultural practices that keep the forest of the community from deforestation.

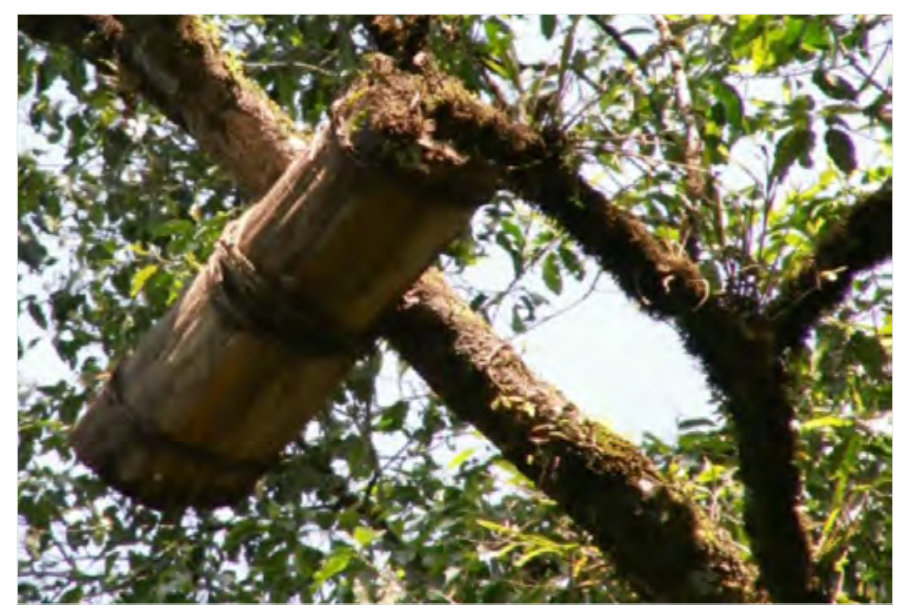

Figure 1: Photo of traditional honey farming in 'Kobbo'

Source: Photo captured by researchers, 2021

Interpersonal conflict is one of the conflict types in Shekacho community, and it occurs due to various reasons. Boundary dispute, disloyalty, if animal belonging to a person damages the farming of the farm holder, and theft are the most common sources of interpersonal conflict that occur in the community.

Conflict in marriage is a type of conflict that occurs between the couple (husband and wife). If the conflict is violent even it will lead to the break of the marriage. 


\section{Procedures Used in the ICRM of Shekacho People}

ICRM of Shekacho People has its procedures which conflict resolution process passes through. The ICRM procedures are part of a well-structured social system geared towards reconciliation, maintenance, and improvement of social stability. The study found that, except the case of reconciliation of a marriage conflict, in all types of conflict, the procedures are common. In the reconciliation of a marriage conflict, the women is not forced to choose an elder, this is done to protect the women from pressure. The procedures in ICRM are deeply rooted in the customs and the traditions of Shekacho people. Therefore, conflict resolution in the community passes through two consecutive phases, intervention and resolution.

The intervention phase: any conflict that occurs in the community of the Shekacho people is intervened as soon as the occurrence of conflict is being known. In the community of Shekacho people, the occurrence of conflict is known in two ways. Firstly, the occurrence of conflict is known when both or either party in the conflict appeal the case to elders aiming to solve the conflict peacefully. This way of revealing the conflict to elders in the community is known as wajiho. Secondly, after the elders get information about the occurrence of conflict, the elders themselves contact the disputants and negotiate them separately to bring the parties into a peaceful resolution of conflict. The rationale behind the intervention in the conflict in the community is to stop the conflict before it becomes broad and destructive and to prevent the potential damage of the conflict. Conflict intervention in the community of Shekacho people includes the following procedures.

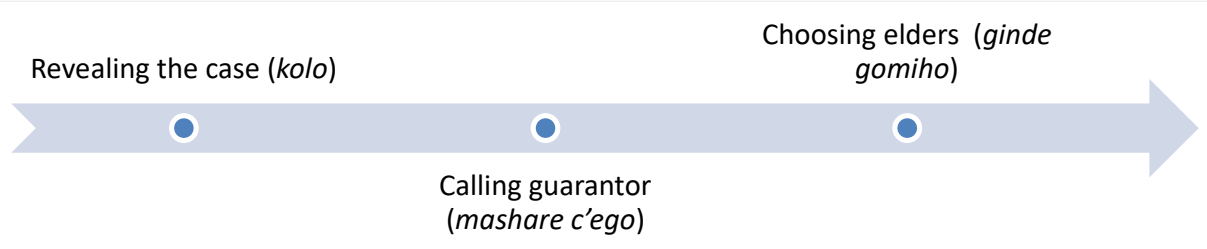

Figure 2: Conflict intervention procedures

Source: researchers' compilation, 2021

Revealing the case; the intervention process of conflict resolution in the Shekacho community begins with revealing the case which is known as kolo. This is also the process of differentiating the accuser from the defendant or victim from the harmer. In this procedure, the case is unambiguously identified and the victim and harmer are differentiated. This task is carried out by the local elders, known as Shawe-Geno, who are well known in the community for their irreplaceable role in resolving conflict and restoring peace. 
Calling guarantor which is called masharec'ego-after the case is identified and the accuser and accused are differentiated they are expected to call their respective guarantor. The guarantor, known as 'masharo' takes the responsibility of convincing the person whom he guarantees to peacefully solve the conflict, to prevent the person whom he guarantees from any wrong action that may disturb the peaceful reconciliation and that may trigger further conflict.

Choosing elders, called Gindegomiho, is a procedure in which both parties in the conflict choose their respective elders who will be responsible to hear the case and resolve the conflict peacefully. The parties in conflict are also expected to identify and choose reserve elders, known as kocho, who carry out the litigation if the main elders are absent due to personal reasons. In Shekacho community, there are two ways of choosing or identifying elders for reconciliation. The first is when both parties in the conflict select their elders and one accepts the others. The second way is when one chooses for the other and when there is acceptance and confirmation from the other side. There is a possibility that one's choice could be rejected by the other. The selection of elders by the parties continues until one accepts and confirms the selection of the other and both parties come to an agreement.

Resolution Phase: This phase follows after ensuring the deterrence of the conflict from further escalation. At this phase, the two parties present their case to the chosen elders and the process of resolution begins which primarily involves litigation, which is known as teggo. This is the proceeding of hearing the argument of disputants turn by turn. The procedure of proceeding litigation is known as tegge-kebbo which is held in front of chosen elders who have been identified by the litigants during the intervention. In the litigation process,the elders permit the conflicting parties to present their argument turn by turn in which the first turn is necessarily given for the plaintiff to present his/ her complaint. This practice is also true in ICRM of the Afrar people where the elders give the plaintiff the first opportunity to explain his/her case (Gebre-Egziabher, 2014). The argument between the disputants is called $\boldsymbol{y} \boldsymbol{a}^{\prime} \mathbf{k o}$. When $\boldsymbol{Y a}^{\prime} \boldsymbol{k} \boldsymbol{o}$ begins, the victim presents either by claiming the compensation from the harmer or only presents his/ her grievance leaving the decision of compensation for elders. If the victim begins $\boldsymbol{y a}_{\mathbf{\prime}} \mathbf{k} \boldsymbol{o}$ demanding compensation from the harmer, the harmer is expected to respond to the demand of the victim and the compensation varies, for instance, an ox, depending on the demand of the victim. Then, the harmer responds to the victim's demand may be by accepting, rejecting, or requesting for the reduction of the demand. In the $\boldsymbol{y} \boldsymbol{a} \boldsymbol{\prime}^{\boldsymbol{k} \boldsymbol{k}} \boldsymbol{\boldsymbol { o }}$, the process of presenting the demand by the victim and response by the harmer is called Tife-yechio or Kube-yechio. 


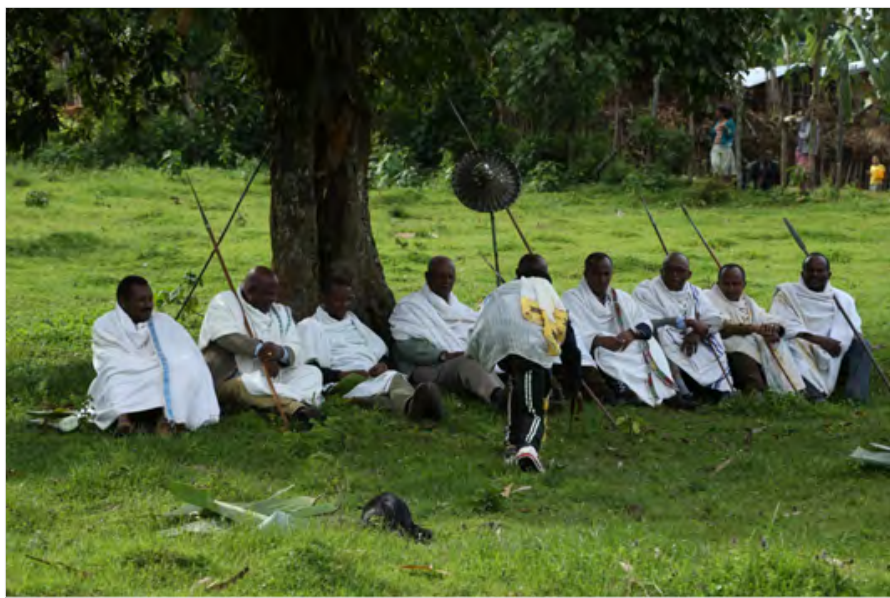

Figure 3: Photo depicting disputants' agreement on the pre-determined compensation called Tife-yechio or Kube-yechio

Source: photo captured by researchers, 2021

After the argument made by the plaintiff, the elders give the chance for the accused to present his/her reaction to the complaint presented by the accuser. The argument between the accuser and the accused continues as long as the permission is given by the elders. The session of resolution may also include providing evidence and witnesses and this depends on the nature of the case. The elders finally come to stop the argument if they believe the two parties have presented and defended exhaustively.

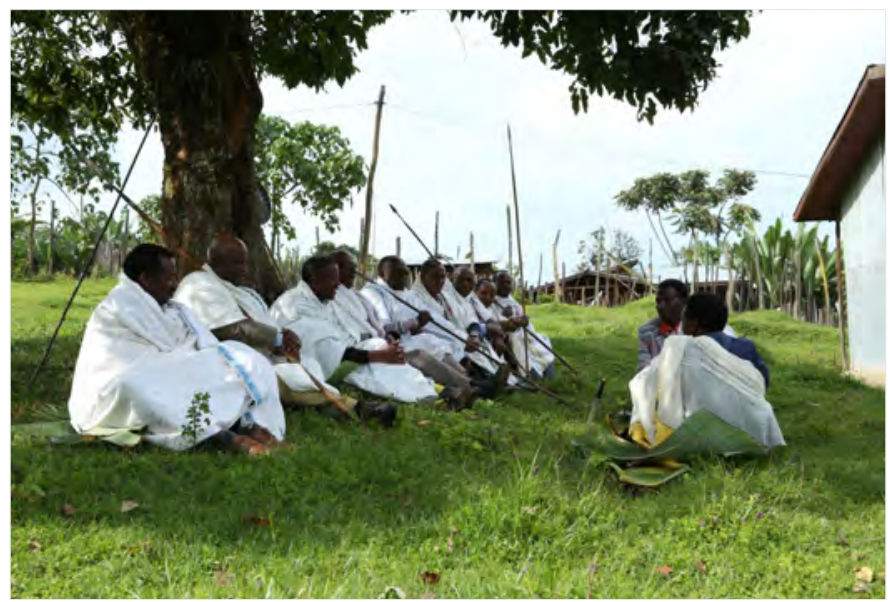

Figure 4: disputants in litigation tego

Source: photo captured by researchers, 2021 
Then the elders order the two parties to go faraway before they make a decision. Then the elders take time to exhaustively discuss the case and make a decision in the absence of the parties in the conflict. After the decision is made, the parties in the conflict are called back to the session and the decision which has been made is announced by the elders. The decision defines the level of the harm with the corresponding amount of compensation, called nummo. Then, the conflicting parties are requested to express their feelings regarding the decision made by the elders and this paves a way for knowing whether the conflicting parties accept or reject the decision. Either party has the right to reject the decision if he/she believes the decision in particular and the litigation process, in general, is unfair and biased. This is called ginde-shago. If this so, the litigant has the right to appeal the case to the next step which is at Gepi-tato interchangeably Gepi-niho (clan leader) level.

On the other hand, if the accuser and the accused agree to accept the decision, further discussion is made on the implementation of the compensation, nummo, in which the amount of the compensation and time of execution is decided. For the Shekacho community, the compensation can be in cash or kind. The compensation in kind can range from hen to cow depending on the type and weight of the case and the victim decides to receive or not to receive the compensation. Most of the time, the victim isn't in a position to receive the compensation because the ICRM centers on forgiveness, reconciliation, and addressing the affected relationship based on the value of truth and justice. In the ICRM of Shekacho people, compensation isn't the target. Rather, the indigenous conflict resolution heavily centers on the notion of restoration of peace with the restoration of social solidarity and reconciliation. Therefore, the ICRM of Shekacho people prioritizes ensuring social harmony, social cohesion, peaceful coexistence, and humanity.

The process of refusing to receive the compensation is called numme-maro in Shekacho community. After the issue of compensation is managed and arranged, the conflicting parties confirm their reconciliation, known as Shoto, by exchanging greetings from bottom of their heart in front of the elders. Therefore, reconciliation or Shoto procedure between the disputants is the practical indication of peaceful resolution of the conflict.

\section{Structure of ICRM of Shekacho People}

ICRM of Shekacho people has its structure through which conflicts are resolved. Conflicts that occur in Shekacho community could easily be handled at grass root levels by the communities themselves through an old-aged system of conflict resolution mechanism. This is a system of resolving conflict at the local level through the intervention of local elders who are known as shawe-geno. However, it can go beyond the local elders as the structure puts the hierarchy through which the resolution of conflict passes. Therefore, the structure of the ICRM of Shekacho people is hierarchical and is deeply rooted in the cultural value of Shekacho people. 


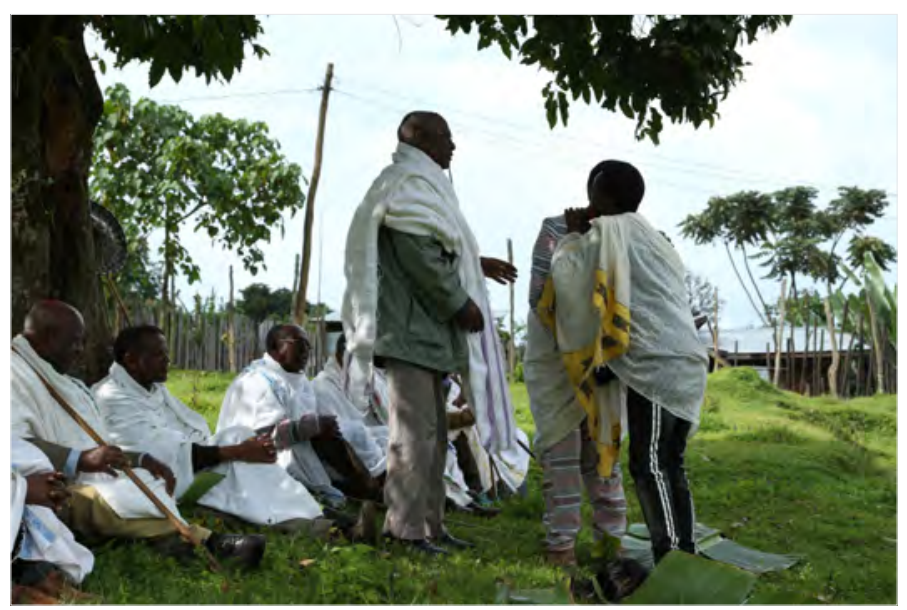

Figure 5: Ceremony of reconciliation Shoto at the end of the litigation tego

Source: photo captured by researchers, 2021

According to the structure of ICRM of the Shekacho people, resolving conflict begins at the village where the conflict was raised. Here, conflict is managed and resolved initially at the village level by the leading role of local elders. Here the conflict is managed as soon as it occurs so that it doesn't escalate and lead to crisis. The local elders try to intervene as soon as the occurrence of conflict is known. The local elders resolve the conflict by bringing the disputants into a negotiation which aims at resolving the disagreement peacefully. However, either party in the conflict may not be satisfied by the decision made by local elders and can reject the decision. If this is so, as per the structure, the local elders hand over the case to the concerned body that is the next responsible body to handle the case in the resolution. This body is a clan leader who is known as Gepi-Tato.

Gepi-Tato in the Shekacho community is the leader of a clan and plays a pivotal role not only in resolving conflict and maintaining peace but also in overall aspects (including administering the resources) of the clan it governs. Therefore, one of the key roles of Gepi-Tato is resolving conflict which arises in his administrative area. Gepi-Tatogets involved in resolving conflict only if the conflicting parties fail to reconcile during resolution held at village level by local elders and only the local elders hand over the case to him. The clan leader tries to resolve the conflict together with selected local elders and can approve the decision made by local elders or can revise and make a new decision. After the decision is made, there is a possibility of conflicting parties accepting or rejecting the decision made by Gepi-Tato (clan leader). In the Shekacho community, conflicting parties usually tend to prefer to accept the decision made by Gepi-Tato because, on the one hand, the clan leader is the most honorable and respected person in his administration area and therefore they are governed by his decision, and on the 
other hand the community members strongly and undoubtedly believe the decision of Gepi-Tato is fair and unbiased. If this is so, conflict resolution is finalized with an arrangement of compensation and a reconciliation ceremony between the conflicting parties. However, there may be a rare case that conflict resolution can go beyond Gepi-Tato. If this is so, it is known as Mikeracho that takes the responsibility of resolving the conflict from Gepi-Tato. Mikeracho begins to take part in resolving conflict after the Gepi-Tato hands over the case to it.

In the indigenous system of governance of the Shekacho people, Mikeracho is a government body that constitute sof nine members which include the king, Tato, the Prime Minister, Keterasha, and seven clan leaders Gepi-Tatos. Primarly, the Mikeracho (the council) has the role of making discussions and passing decisions on the overall affairs of the Shekacho people.

Concerning conflict resolution, Mikerecho members can hold conflict resolution talks with the leadership of Keterasha who is the prime leader of Mikerecho or the council. After exhaustively discussing the case, the council makes a decision which can be endorsing the decision of Gepi-Tato or a new decision by revising the previous one made at Gepi-Tato level. After the decision is made, conflicting parties decide to accept or reject the decision made by Mikerecho (council). If the decision is accepted by both conflicting parties, conflict resolution is finalized with an arrangement of compensation and a reconciliation ceremony between the conflicting parties. On the other hand, if either party refuses to accept the decision made by this body, the conflict resolution goes beyond Mikerecho. It is the King, known as Tato, who takes the responsibility of resolving conflict after this stage.

With the coordination of Keterasha and leadership of the Tato,the case is discussed in detail and a decision is made at yebo where the king himself addresses justice and the decision becomes final and binding. This is the highest level of the structure of ICRM of Shekacho people. It is so rare that conflict cases reach this highest level because most conflicts are resolved at lower levels of structure especially at local elders (Shawe-Geno) and clan leader (Gepi-Tato) levels.

\section{Actors in ICRM of Shekacho People}

Different actors take part in resolving conflict through ICRM of Shekacho People. The issue of which and how many actors are involved in resolving conflict depends on the level where the conflict is resolved. Any conflict that arises in the Shekacho Community is resolved at different levels as per the structure displayed in figure 5.

Actors at the local level: in Shekacho Community, conflict is usually resolved by local elders (shawe-geno) at the local level where the conflict happened. At this level of resolving conflict, the actors are elders and conflicting parties or the accuser and the 


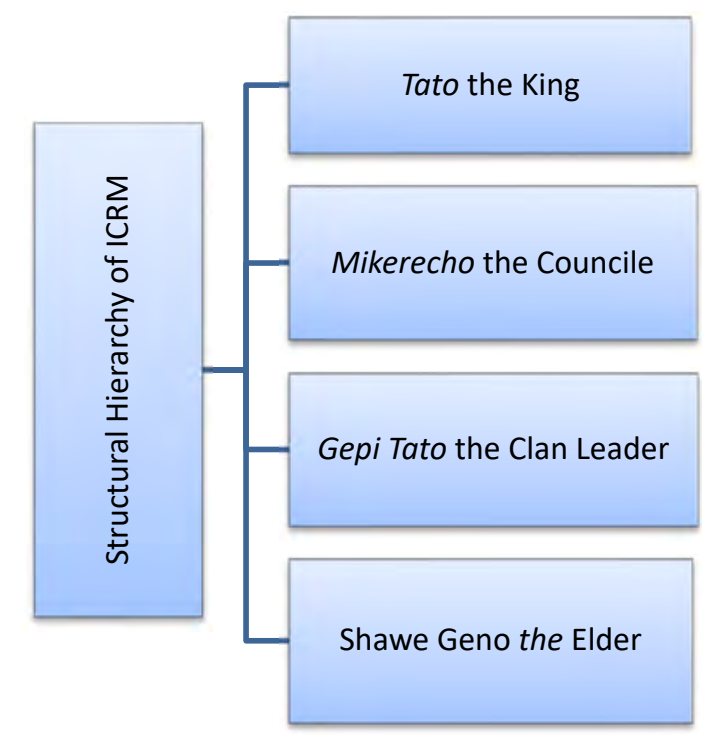

Figure 6:The hierarchical structure of ICRM of Shekacho People

Source: Researchers compilation, 2021

accused. At the local level, it is elders, who are called Shawe-Geno or interchangeably Shawe-Ogo, who play a key role in resolving conflict and restoring peace. The elders can be identified and selected, depending on the interest of the conflicting parties, from the elders in the community. The local elders are concerned with making morally and socially acceptable decisions to foster good relationships between the parties in the conflict and therefore the whole community.

Actors at Gepi-Tato level: conflict is also resolved at Gepi-Tato level in the Shekacho community when it is not solved at the local level due to the disagreement to accept the decision made by the elders. The Gepi-Tato (the clan leader) with selected elders resolves the conflict at this level. Therefore, the clan leader and the elders are the actors at this level of conflict resolution. However, Gepi-Tato is the most significant actor not only at this level of resolving conflict but also in ICRM of Shekacho people in general. In Shekacho community, Gepi-Tato refrains from taking any food and drink as soon as he hears the rise of conflict and keeps fasting until he can resolve the conflict and he ensures the restoration of peace. Therefore, the parties in the conflict are expected to expose themselves as soon as possible to obey the Gepi-Tato and his act, and then the respective clan leader immediately gets involved in and resolves the conflict. In Shekacho community, it is the Gepi-Tato who interrupts in and resolves serious conflicts like the bloody ones. 
Actors at Mikerecho, interchangeably Mikere Ogo level: the members of Mikerecho (council) are the actors who involve in resolving conflict at this level. With the leading role of Keterasha whose role is like a prime minister in the modern governance, the case thatis not resolved at Gepi-Tato is resolved at this level. At this level, the case comes to Mikerecho by a Gepi-Tato who handled the issue prior in his respective administration. However, the chance of reaching a case at this level is rare in ICRM of Shekacho people.

Actors at Tato level: at this level, the King, called Tato, and members of Mikerecho are the actors who take part in resolving conflict. This is the final level and a case of conflict reaches this level if it is not resolved at the lower levels, including Mikerecho. Tato (the king) takes the leading role in resolving conflict at this level and the decision made at this level is called mariam-cherato. The decision made at this level becomes the final and binding one. Like at Mikerecho level, the chance of reaching a case at this level is rare.

\section{Woraffo in the ICRM of Shekacho people}

In Shekacho community, Worafo in its literal and general connotation refers to blameless or guiltless and the process is called purification. Accordingly, the term is used to express one's purification or guiltlessness from any wrongdoing. Worafo is also used to express one's excellence regarding his/her discipline, industriousness, social acceptance, and good manner.

Worafo plays a very irreplaceable role in resolving conflict in particular and in promoting peace in general in Shekacho community. Worafo is predominantly used as a tool for promoting peace in the community because it is Worafo that is applied to identify the wrongdoers who destabilize peace and cause trouble in one or another way in the community. Shekacho community, it is Gepi-Tato (clan leader) who holds the ceremony of Worafo. Worafo ceremony takes place with the leadership of Gepi-Tato in the presence of elders and the whole members of the village where the problem has occurred. Gepi-Tato plays a very decisive role not only in leading and executing Worafo but also in resolving conflict, restoring and maintaining the peace of the clan where he governs. Therefore, Worafo is a system that Gepi-Tato uses to resolve conflicts and maintain peace in the community at large.

There are clear procedures and processes through which the Worafo is executed. After the Gepi-Tato knew trouble happened, which could be stealing, robbing, beating, burning house, etc., he passes orders through local elders, to all members of the community so that they are gathered for meeting on the problem happened. After the Gepi-Tato ensures the gathering of the people, he declares the opening of Worafo ceremony by revealing the case to be investigated. Before the investigation begins, the Gepi-Tato strongly notices the people to be truthful and to avoid any kind of bias for instance based on family connections, friendship, or intimacy, and merely focus on truth. Truth is the central principle of Worafoin particular and indigenous conflict resolution of Shekacho people 
in general. Then, each person, turn by turn, stands in front of the Gepi-Tato and in front of the people to listen to the critique of the people about his personality that is either he/she is rewarded or denied blameless (Worafo). Then, Gepi-Tato asks the people to publically and collectively make their critique on the discipline of the person and the ceremony continues until each person passes through this way. Then, this investigation, by default, clearly differentiates those who are rewarded Worafoand those who are denied Worafo. Then, further investigation, by the Gepi-Tato, is made on those who have been denied Worafo to find out the person who has been engaged in the act of wrongdoing. Here, the Gepi-Tato plays a key role in the investigation and in identifying the wrongdoer because Gepi-Tato is so honorable and respectable person in the cultural value of Shekacho people. Then, finally, the suspected persons either admit or deny the action in which he/she was suspected. If he/she refuses and the investigation finds out no troublesome, the Gepi-Tato publicly curses the hidden and unseen troublesome to be punished by the power of God and Worafo ceremony comes to an end. The curse of Gepi-Tato is believed to lead to mysterious death or sickness. The words of Gepi-Tato are bitter and those who have caused troubles are often punished.

\section{The Nexus Between ICRM of Shekacho People and the Formal Court System}

No single conflict resolution mechanism is a perfect fit for all types of conflict. The types of conflict resolution used differ largely depending on the type, nature, and level of conflict. Accordingly, conflict can be resolved either by the formal court or using an informal (alternative) dispute resolution mechanism. Although the formal court system is the common mechanism of conflict resolution in modern society, indigenous (informal) conflict resolution is an alternative mechanism of resolving conflict in many societies. Therefore, conflict could be resolved either indigenously or in a formal court system in different parts of the world which is also true in Shekacho community. The relationship between these resolution mechanisms of handling conflict could have a significant impact on the overall peace-building process and there may be strong or loose relation between these the ICRM and the formal court system.

The relationship between the ICRM and the formal court system, in one or another way, affects their role in resolving conflict and promoting sustainable peace. The high and high the relationship between them, the more and more they are effective in their function. Thus study reveals that the relationship between the indigenous institution and the formal court system is currently loose in Sheka Zone. The formal court does not have a system that enables it to establish a formal relationship with the indigenous institution. Therefore, the relationship is informal and the court does not formally encourage and support ICRM despite the decisive and bold role of the indigenous institution in resolving conflict and maintaining sustainable peace at large. The ICRM is not capacitated to effectively play its role in resolving conflict and peacebuilding. The formal court system gives no attention to the ICRM of Shekacho people. 
However, the formal court sends some cases, based on the type of case and willingness of conflicting parties, to elders (Shawe-Geno) and clan leaders (Gepi-Tato) to be solved through ICRM because solving conflict this way is more valuable in terms of many things. Many people prefer the indigenous way of resolving conflict as it saves their cost, time, and energy. It is considered the easiest and fastest way to reach an agreement and restore peace. The indigenous mechanism of resolving conflict gives high attention to the justice of the resolution which has a constructive and long-lasting impact on the establishment of harmonious interaction and restoration of sustainable peace in the post-conflict period. Despite the loose relation and weak support from the formal court, the ICRM is still strongly functional and the elders are playing their bold role in maintaining sustainable peace in Shekacho community.

\section{Trust and Preference to ICRM of Shekacho}

In the Shekacho community, the ICRM is highly trusted. Regardless of where the disputants came from, their economic background, social class, and differences the institution equally treat all social segments, and the decisions made in the institution are believed to be fair and justifiable. Thus, ICRM of Shekacho people is a trustworthy institution among the community. Due to this reason, individuals who come to appeal their grievance to the elders and clan leaders about a given body hold full trust and reliance on the elders and clan leaders.

Consequently, the Shekacho's communities prefer the ICRM against the formal court system. This is because the communities believe that they know the procedures and adjudication process of ICRM very well and issues can be settled within a shortened period as a result justice in ICRM Shekacho can be provided in time. They also argue that if their cases are seen by elders or clan leaders they can be saved from money and energy loss which can be resulted from a prolonged litigation process in the formal court system. There is a strong belief that ICRM sustainably heals the grievances of the disputants. In the indigenous system, both bodies at the end of the adjudication equally satisfy and heal from their grievances and they show this by shaking hands and hugging each other. Another reason is that compared to the formal court system in the indigenous system honest reconciliation can be reached between the conflicting bodies putting aside their grievance. Whereas, the formal court system emphasizes punishment based on a win-lose approach. In line with this finding Chereji \& Wratto (2013), in their comparative study of traditional conflict resolution methods in Liberia and Ghana, argued that traditional institutions emphasize re-conciliation as opposed to Western practices, which place the accent on punishment. 


\section{Threats that are Flagging the Institution}

The study shows that the following are major factors threatening the continuity of the practice.

- Religious teachings: this is a primary threat to the indigenous institution. Religious teachers consider this indigenous practice especially led by clan leaders as traditional ritual practice and they condemn people not to go to clan leaders for such issues.

- The institution has no support from the government. The government doesn't support the elders and clan leaders who work in settling conflicts. Only the government calls clan leaders and elders when it faces a problem.

- The government doesn't give attention to the institution.

\section{Conclusion}

Based on the findings, this study draws the following conclusions on four major themes. Conflict in Shekacho community occurs due to different reasons and such conflicts can be labeled as boundary conflict, conflict in marriage, and interpersonal conflict.

Boundary conflict is the most occurring and common type of conflict among the Shekacho community which falls under two categories these are; clan boundary conflict and interpersonal boundary conflict. Compared to interpersonal boundary conflict clan boundary conflict is violent if not managed in time, and it is the biggest boundary conflict as it involves many families and members of each clan. Interpersonal conflict is one of the conflict types in Shekacho community, and it occurs due to boundary dispute, disloyalty if animal belonging to a person damages the farming of the farm holder and theft are the most common sources of interpersonal conflict that occur in the community.

To resolve such conflicts, the Shekacho community has developed an old-aged system of conflict resolution which has organized procedure, structure, and actors who actively participate in the conflict resolution system. The procedures in ICRM are deeply rooted in the customs and the traditions of Shekacho people. The procedures in ICRM pass through two sequential phases of conflict resolution these are intervention in the conflict phase and resolving the conflict phase. In both phases, there are also procedural sequences that can successfully drive the disputants to the final reconciliation ceremony. Structurally the conflict resolution begins from the elders' level up to the highest level called the king or 'tato'. At each level, known actors are participating in the process of conflict resolution.

The relationship between the indigenous institution and the formal court system is currently loose in Sheka Zone. The formal court doesn't have a system that enables it to establish a formal relationship with the indigenous institution. Therefore, the relationship is informal and the court does not formally encourage and support ICRM 
despite the decisive and bold role of the indigenous institution in resolving conflict and maintaining peace at large.

CRM of Shekacho people is a trustworthy institution among the community. Decisions that are made by the elders and clan leaders are considered to be fair and just. Due to this reason, individuals who come to appeal their grievance to the elders and clan leaders about a given body hold full trust and reliance on the elders and clan leaders.

Religious teachings are the primary threats to the indigenous institution of the Shekacho people. Religious teachers consider the indigenous practice especially led by clan leaders as traditional ritual practice and they condemn people not to go to clan leaders for such issues. Lack of support from the government is also another challenge that is weakening the institution. In general, despite the big role of the indigenous knowledge in maintaining peace and good governance the attention to the institution is very minimal.

\section{Recommendation}

Based on the problems pinpointed from the finding, and suggestions given by research participants researchers like to boldly forward the following recommendations. The recommendations given are categorized under stakeholders who are responsible to preserve and ensure the continuity of this knowledge.

1. From the government side, the following actions have to be done:

- To be able to transfer the knowledge to the next generation; the government has to raise public understanding about ICRM at kebele level, government should give advisory support to elders and clan leaders, build the capacity of clan leaders by finance, and renewing clan leaders compound and preserving it from damage;

- It is clear that; conflict can be resolved using either a formal court or informal conflict resolution system. Although the formal court system is the common mechanism of conflict resolution in modern society, the indigenous (informal) conflict resolution system is also an alternative mechanism of resolving conflict in many societies including Shekacho people. This is because, as we have learned in experience and literature, there is no single conflict resolution mechanism that is a perfect fit for all types of conflict. Thus, the relationship between formal and informal (indigenous) conflict resolution mechanisms is crucial. The relationship between the ICRM and formal court system, in one or another way, affects their role in resolving conflict and promoting peace. If the formal court has closely worked with ICRM of Shekacho people it would have been easy to maintain sustainable peace. Thus, we recommend the local government take the following activities in ensuring the establishment of an interactive relationship between a formal court and the indigenous conflict resolution system.

- Discussing with local elders and clan leaders on issues of cooperation on governance. 
- Identifying and officially recognizing elders and clan leaders and sting ground for the establishment of a relationship with the formal court system.

- Letting representatives of elders and clan leaders take experience sharing from other ethnic groups of Ethiopia on issues how to integrate the indigenous system to the formal court system.

- Communicating with the higher academic institutions for advisory support.

2. From the higher academic institutions side, the following actions have to be done:

- Giving training to elders and clan leaders in collaboration with the local government, giving training to the youth about culture, teaching the youth to differentiate culture, and religious practices. Furthermore, holding symposiums to share and discuss the role of elders, clan leaders, and the indigenous governance system in the modern governance system.

\section{Reference}

1. Awash, E. (2015). Indigenous conflict resolution institutions: A study among the Goffa people of Dumba Goffa District. Addis Ababa University.

2. Braun, V., \& Clarke, V. (2006). Using thematic analysis in psychology. Qualitative Research in Psychology, 3(2), 77-101.

3. Chereji, C., \& Wratto, C. (2013). West Africa. A Comparative Study of Traditional Conflict Resolution Methods in Liberia and Ghana. Conflict Studies Quarterly, 5, 3-18.

4. Chereji, C., \& Sandu, C. (2018). Romania: The Kris procedures. A brief incursion in the Roma community-based dispute management mechanism. Conflict Studies Quarterly, 24, 3-11.

5. Creswell, J. (2007). Qualitative inquiry and research design: Choosing among five approaches. Sage.

6. Edossa, D. (2005). Indigenous Systems of Conflict Resolution in Oromia, Ethiopia. International Workshop on 'African Water Laws: Plural Legislative Frameworks for Rural Water. Johannesburg, South Africa.

7. Endalcachew, B., Gashaw, A., \& Zelalem, M. (2015). Traditional Conflict Resolution as a Better Option to Court Proceeding: An Attitude and Practice in Ambo Town. International Journal of Multidisciplinary and Current Research, 3 (March/April 2015 issue) 206-208

8. Enyew, E. (2014). Ethiopian Customary Dispute Resolution Mechanisms: Forms of Re-storative justice? African Journal of Conflict Resolution, 14(1), 125-154.

9. Fisher, R. (1990). International Peace and Conflict Resolution. School of International Service, American university.

10. Gebre-Egziabher, K. (2014, December 1). Dispute Resolution Mechanisms among the Afar people of Ethiopia and Their Contribution to the Development Process. The Journal for Transdisciplinary Research in Southern Africa, 10(3) 152-164

11. Gowok, S. (2008). Alternative Dispute Resolution in Ethiopia: A legal Framework. African Research Review, 2 (2) 265-285. 
12. Katz, N., \& McNulty, K. (1994). Conflict Resolution. Retrieved Julay 14, 2021, from https:// www.maxwell.syr.edu/uploadedFiles/parcc/cmc/Conflict\%20Resolution\%20NK.pdf

13. Kawulich, B. (2004). Qualitative Data Analysis Techniques. Research Gate (pp. 96-113). Amsterdam: State University of West Georgia.

14. McCandless, E., \& Bangura, A. (2007). Peace Research for Africa: Critical Essays on Methodology. (M. King, \& E. Sall, Eds.) Switzerland: University for Peace.

15. Mack, N. (2005). Qualitative Research Methods: A Data Collector's Field Guide . North Carolina: Research Triangle Park.

16. Masenya, T. (2021). Indigenous Conflict Resolution Systems: Building Cultural Peace and Social Solidarity Among Indigenous Communities in South Africa. Durban, South Africa: Durban University of Technology.

17. Mengesha, A., Yesuf, S., \& Gebre, T. (2015, February 11). Indigenous Conflict Resolution Mechanisms Among the Kembata Society. American Journal of Educational Research, 3(2), 225-242.

18. Mussa, M., Teka, H., \& Aliye, A. (2017, December). Indigenous Conflict Management and Resolution Mechanisms on Rangelands in Pastoral Areas, Ethiopia. Journal of African Studies and Development, 10(9), 112-117.

19. Nicholson, M. (1992). Rationality And The Analysis Of International Conflict. New York, USA: Cambridge University Press.

20. Olsen, D. (2010, October 20). Cultural Heritage and Tourism in the Developing World: A Regional Perspective. (J. Dallen, G. P. Timothy, Nyaupane, \& Abingdon, Eds.) Journal of Heritage Tourism, 5(3), 251-252.

21. Osei-Hwedie, K. (2012). kaiptc.org. Retrieved September 5, 2021, from Kaiptc: https:// www.kaiptc.org/kaiptc-publication/indigenous-conflict-resolution-in-africa-the-caseof-ghana-and-botswana-in-b-z-osei-hwedie-t-galvin-h-shinoda-eds-indigenous-meth ods-of-peacebuilding-hiroshima-ipshu-pp-33-51-with-ran/

22. Peters, I. (2006, March 16). Conflict Management: Paper Presnted at a Workshop of on Conflict Resolution Organized by Nigeria Network of Non Governmental Organizions. Ibadan, Nigeria.

23. Robin, P. (1996). Organizational Behavior: Concepts, Controversies and Applications: 7th edition. Printing Hall.

24. Sandu, C. (2018). Romania: Traditional conflict resolution mechanisms used by the Roma communities. Conflict Studies Quarterly, 22, 95-108.

25. Thakore, D. (2013). Conflict and Conflict Management. IOSR Journal of Business and Management (IOSR-JBM), 8 (6), 07-16.

26. Vaismoradi, M., \& Snelgrove, S. (2019). Theme in Qualitative Content Analysis and Thematic Analysis. Forum Qualitative Sozialforschung, 20(3), 23-36.

27. Vaismoradi, M., Bondas, T., \& Turunen, H. (2013, March 11). Content Analysis and Thematic Analysis: Implications for Conducting a Qualitative Descriptive Study. Qualitative Descriptive Study, 15(3), 398-405. 